\title{
İntertrokanterik kırık sonrası nadir görülen bir parsiyel protez çıkığı
}

\author{
Adnan Kara ${ }^{1}$, Yunus Öđç${ }^{1}$, Ali Şeker ${ }^{1}$, Metin Uzun ${ }^{2}$, Erden Ertürer ${ }^{1}$, İrfan Öztürk ${ }^{1}$
}

\begin{abstract}
ÖZET:
Intertrokanterik kırık sonrası nadir görülen bir parsiyel protez çıkığı

Kalça kırığı sonrası uygulanan parsiyel protezlere bağlı çıkıklar, karşılaşılabilecek komplikasyonlar arasındadır. Bu çıkıklar femoral başın bir bütün şeklinde doğal asetabulumdan ayrılması şeklinde görülür. Bizim olgumuzda ise intertrokanterik femur kırığı nedeniyle 2002 yılında kalkar destekli Leinbach tipi parsiyel protez uygulaması sonrası femoral baş ile stem arasında çıkık meydana gelmiştir. Parsiyel protezin baş kısmı asetabulumda kalmış, femoral stem ise posterosuperior yönde çıkmıştır. Bu yazıda baş boyun replasmanlı parsiyel protezlerde baş ve boyun uyumsuzluğu olduğunda atipik protez çıkıkları gelişebileceği vurgulanmak istenmiştir.

Anahtar kelimeler: Intertrokanterik kırık, Kalça kırığı, Leinbach protez, Parsiyel protez

ABSTRACT:

A rare type of dislocation of hemiarthroplasty after intertrochanteric fracture Dislocation of hemiarthroplasty after hip fracture surgery is a rare complication and mostly occurs as a total luxation of head from acetabulum. In our case, dislocation occured between head of prosthesis and femoral stem after operation with Leinbach type hemiarthroplasty due to intertrochanteric femur fracture. Although head of prosthesis stayed in acetabulum, femoral stem luxated posterosuperiorly. This study aims to emphesize the risk of atypic dislocation in case of incongruency of head and femoral stem of hemiarthroplasty.

Key words: Intertrochanteric fracture, hip fracture, Leinbach prosthesis, hemiarthroplasty
\end{abstract}

Ş.E.E.A.H. Tıp Bülteni 2013;47(3):154-156

\section{'Şişli Etfal Eğitim ve Araştırma Hastanesi Ortopedi ve Travmatoloji Kliniği, Istanbul-Türkiye \\ ${ }^{2}$ Maslak Acıbadem Hastanesi Ortopedi ve Travmatoloji, İstanbul-Türkiye}

Yazışma Adresi / Address reprint requests to: Uzm. Dr. Adnan Kara, Şişli Etfal Eğitim Ve Araştırma Hastanesi Ortopedi ve Travmatoloji Kliniği, İstanbul-Türkiye

Telefon / Phone: +90-212-373-5000/6515

E-posta / E-mail:

dradnankara@gmail.com

Geliş tarihi / Date of receipt:

23 Ekim 2012 / October 23, 2012

Kabul tarihi / Date of acceptance: 9 Kasım 2012 / November 92012

\section{GiRiş}

Stabil olmayan intertrokanterik kırıklarda uygulanan internal tespit yöntemleri sonrası kaynama güçlüğü, materyal yetmezliğine bağlı kırılma, baştan sıyrılma gibi komplikasyonların oluştuğu bildirilmektedir (1). Öztürk ve ark. kalça kırı̆̆ı nedeniyle ameliyat edilen 65 yaş üstü hastalarda bir yıllık ölüm oranlarını, düşük risk grubunda \%6.9, orta risk grubunda $\% 31.4$, yüksek risk grubunda ise \%80 olarak belirtmişlerdir (2). Bu hastalarda hedef, erken dönemde mobilizasyonu sağlayarak hastayı kırık öncesi fonksiyonel durumuna getirmeyi ve böylece olası komplikasyonların gelişimini önlemektir (3). Sancheti ve ark. osteporotik intertrokanterik kırığı olan yaşlı hastalarda parsiyel protez uygulaması sonrasında hastaların \%91 inin kırık öncesi fonksiyonlarına dönebildiğini ve operasyon sonrası yük verme sorunu yaşan- madığı için erken dönemde iyi sonuçlar alınabileceğini belirtmişlerdir. Bu nedenle genel durumu iyi olmayan, osteoporotik, görme ve işitme kaybı gibi işlevsel kısıtlılıkları olan internal fiksasyon sonrası kontrollü rehabilitasyonun mümkün olamadığı hastalarda unipolar veya bipolar hemiartroplasti uygulanan bir tedavi yöntemidir (4).

\section{OLGU}

Bizim olgumuzda 2002 yılında evde düşme sonrası tarafımıza başvuran ve intertrokanterik femur kırığı tespit edilen 64 yaşındaki bayan hastaya Leinbach tipi baş, boyun replasman protezi uygulandı (Resim 1). Hasta ameliyat sonrası ikinci ayında ayakta kısalık, rotasyon ve kalça ağrısı nedeniyle tarafımıza yeniden başvurdu. Sistemik hastalıkları ve diyabetik retinopati nedeniyle görme problemi olan hasta- 


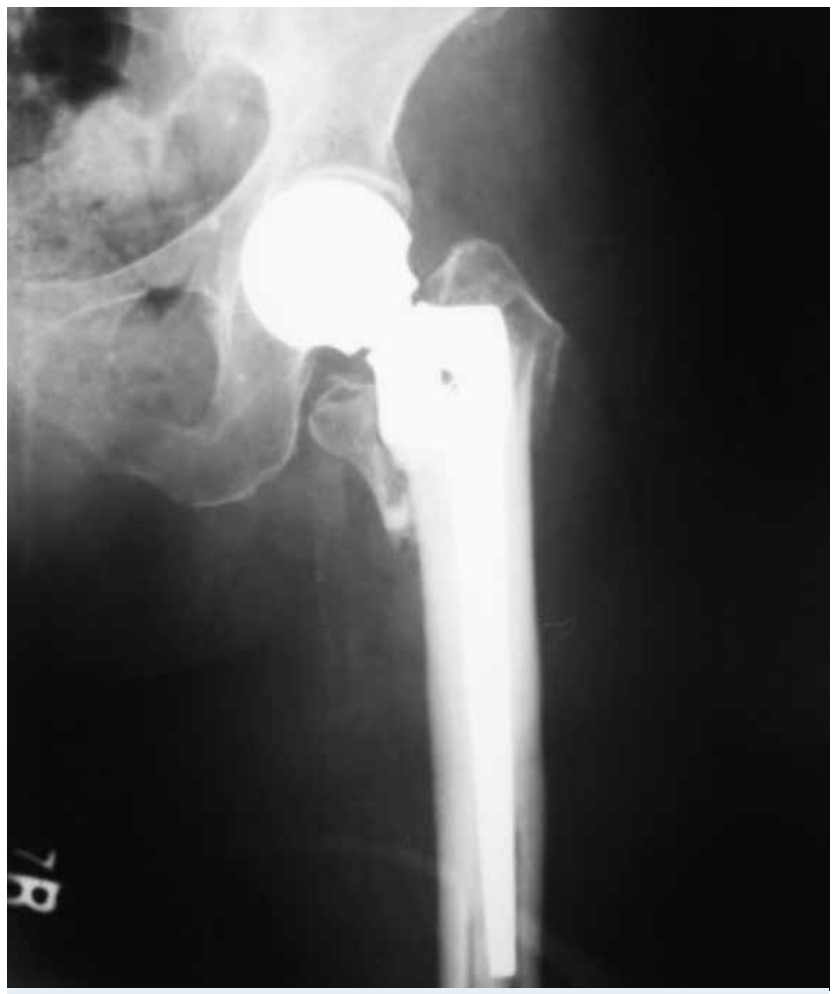

Resim 1: Ameliyat sonrası parsiyel protezin görüntüsü

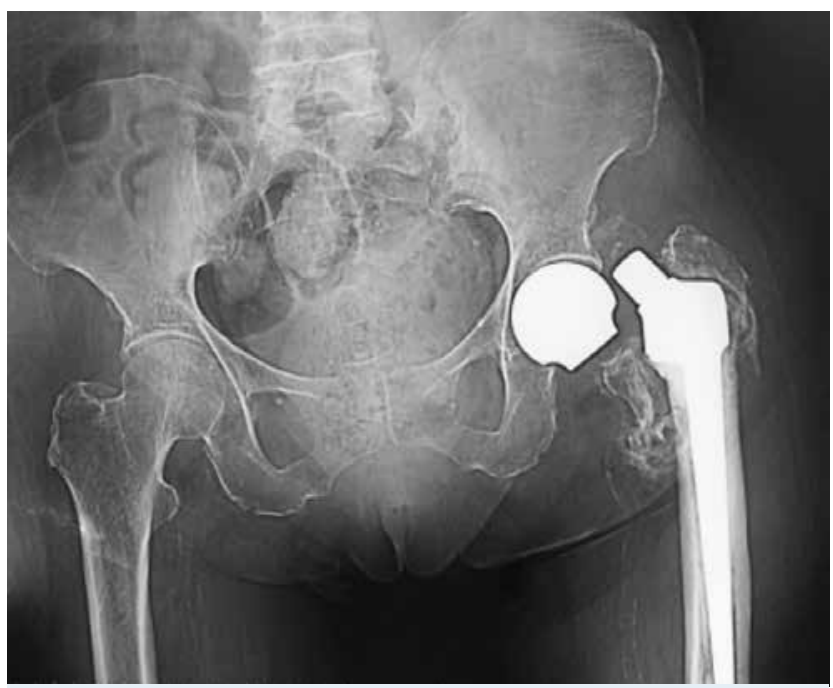

Resim 2: Parsiyel protezin atipik çıkık görüntüsü

nın evde mobilize olamadığı ve düşme hikayesinin olmadığı öğrenildi. Hastanın çekilen grafilerinde Leinbach protezin baş kısmının asetabulumda, femoral stemin ise posterosuperiorda görüldüğü atipik protez çıkığının tespit edilmesi üzerine açık redüksiyon yapılarak kalça tekrar redükte edildi (Resim 2,3).

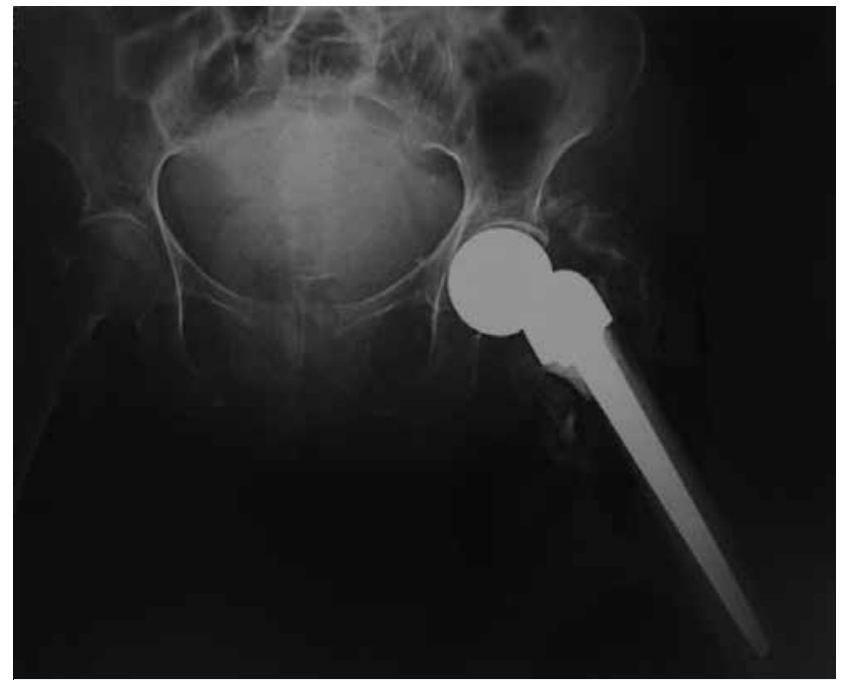

Resim 3: Redüksiyon sonrası parsiyel protezin görüntüsü

\section{TARTIŞMA}

Klasik parsiyel protez çıkığı femoral başın bir bütün şeklinde doğal asetabulumdan ayrılması şeklinde görülür. Madarat ve ark. posterolateral girişim ile sementli unipolar kalça parsiyel protezi yapılan 602 hastada $34(\% 5,6)$ çıkık olgusu bildirmişlerdir (5). Stabil olmayan intertrokanterik kırıklarda Kıral ve ark. yayınladığı 24 hastalık Leinbach tipi parsiyel protez serisinde iki olguda erken dönemde tespit edilen posterior çıkık için kapalı redüksiyon uygulanmış, bunların hepsi protezin doğal asetabulumdan ayrılması şeklinde görülmüştür (6). Femoral komponent ile asetabuler komponent arasında ayrışma olması ve femoral komponentin asetabuler komponentten ayrı bir şekilde çıkık oluşturması çok nadir görülen bir çıkık şeklidir. Literatürde bipolar parsiyel protez uygulaması sonrası polietilenden kaynaklanan sınırlı sayıda atipik çıkık olgusu bildirilmektedir. Bateman ve ark. yaptığı çalışmada bipolar parsiyel protez sonrası üç hastada polietilen kırılmasından, yine Incavo ve ark. üç hastada polietilen liner bozulmasından kaynaklanan atipik çıkık olgusu bildirmişlerdir $(7,8)$.

İntertrokanterik kırıklarda sıklıkla kemiğin kalkar bölgesi de hasarlandığı için kullanılan protezin kalkar destekli olması tercih edilmektedir. Leinbach protezin bu yıllarda yerli imalat nedeniyle kolay temin edilebilmesi, kemik çimentosu ile kullanılabil- 
mesi, çeşitli boyun ve sap uzunluklarının bulunması, yaşlı ve osteoporotik hastaların intertrokanterik kırıklarının tedavisinde tercih nedeni olmuştur. Bizim hastamızda erken dönemde çıkık görülmemesini hastanın görme problemleri nedeni ile erken mobili-

\section{KAYNAKLAR}

1. Uzun M, Ertürer E, Oztürk I, Akman S, Seçkin F, Ozçelik IB. Long-term radiographic complications following treatment of unstable intertrochanteric femoral fractures with the proximal femoral nail and effects on functional results. Acta Orthop Traumatol Turc 2009;43(6):457-63.

2. Oztürk I, Toker S, Ertürer E, Aksoy B, Seçkin F. Analysis of risk factors affecting mortality in elderly patients (aged over 65 years) operated on for hip fractures. Acta Orthop Traumatol Turc 2008;42(1):16-21.

3. Pajarinen J, Lindahl J, Michelsson O, Savolainen V, Hirvensalo E. Pertrochanteric femoral fractures treated with a dynamic hip screw or a proximal femoral nail. A randomised study comparing post-operative rehabilitation. J Bone Joint Surg Br 2005;87:76-81.

4. Sancheti Kh, Sancheti P, Shyam A, Patil S, Dhariwal Q, Joshi R. Primary hemiarthroplasty for unstable osteoporotic intertrochanteric fractures in the elderly: A retrospective case series. Indian J Orthop 2010;44(4):428-34. ze olamamasına, atipik kalça çıkığının ise kullanılan Leinbach tipi baş boyun replasman protezinde polietilen bulunmamasından dolayı protezdeki baş, boyun uyumsuzluğundan kaynaklandığını düşünmekteyiz.

5. Madanat $R$, Makinen TJ, Ovaska MT, Soiva M, Vahlberg $T$, Haapala J. Dislocation of hip hemiarthroplasty following posterolateral surgical approach: a nested case-control study. Int Orthop 2012;36(5):935-40.

6. A Kıral, M Kuskucu, H Kaplan, K Çuhadar, A Sarıdoğan, A Yaşar. Primary hemiarthroplasty with Leinbach prosthesis in the treatment of unstable intertrochanteric and subtrochanteric hip fractures. Acta Orthop Traumatol Turc 1993;27(3):187-91.

7. Barmada $R$, Mess D. Bateman hemiarthroplasty component disassembly. A report of three cases of high-density polyethylene failure. Clin Orthop Relat Res 1987;224:147-9.

8. Incavo SJ, Ninomiya J, Howe JG, Mayor MB. Failure of the polyethylene liner leading to notching of the femoral component in bipolar prostheses. Orthop Rev 1993;22(6):728-32. 